Article

\title{
Genetic Gain for Yield and Allelic Diversity over 35 Years of Durum Wheat Breeding at ICARDA
}

\author{
Filippo Maria Bassi *, Mikael Miloudi Nachit \\ International Center for Agricultural Research in Dry Areas, Rabat 10000, \\ Morocco \\ * Correspondence: Filippo M Bassi, Email: f.bassi@cgiar.org; \\ Tel.: +212-5-37681659.
}

\section{ABSTRACT}

The ICARDA's durum wheat breeding program was established in 1977 in Aleppo, Syria, where it continued its work targeted to the drylands of the developing world until 2012, when it was forced to relocate. This movement represented an occasion to measure the impact of 35 years of public breeding via a detailed genetic gain (GG) study. A total of 22 ICARDA's historical entries representing three decades of work (1974-1984, 1985-1994, or 1995-2004), were placed in competition with elites from the most recent decade (2005-2011). A total of 10 environments and 7 sites were used for the assessment. Decade-wise GG for grain yield was measured to reveal $>9 \%$ (equal $0.9 \%$ per year) at 8 of the environments, while no progress was found for the dry and cold conditions of the Atlas Mountains. Combined analysis revealed an average GG per year of $0.7 \%$, mostly driven by earlier flowering and an increase in spike density. The germplasm was also characterized with 60 polymorphic SNPs to reveal that the breeding process has already eroded $6.3 \%$ of the original genetic diversity, and that over 3-folds reduction has occurred for rare alleles. Clustering analysis confirmed that two sub-populations have substantially disappeared under the breeding selection pressure. The results presented here show that good progress was made till now, but at the cost of reducing genetic diversity and pushing toward very early genotypes. A revamped strategy is then needed to continue delivering germplasm that is meaningful to breeders worldwide.

\section{G Open Access}

Received: 14 June 2019

Accepted: 02 July 2019

Published: 03 July 2019

Copyright (c) 2019 by the author(s). Licensee Hapres, London, United Kingdom. This is an open access article distributed under the terms and conditions of Creative Commons Attribution $\underline{4.0}$ International License.
KEYWORDS: genetic gain; grain yield; ICARDA; spike density; drought

\section{ABBREVIATIONS}

GG, genetic gain; GY, grain yield; TKW, 1000-kernels weight

\section{INTRODUCTION}

The durum wheat breeding program of the International Center for Agricultural Research in Dry Areas (ICARDA) was funded in 1977 in Aleppo, Syria. Its original scope was to serve as a regional test site for selection of elite lines and segregating populations generated in Mexico by the 
International Maize and Wheat Improvement Center (CIMMYT), with a specific focus on selecting germplasm for the non-tropical drylands of the developing world [1]. Since 1981, the ICARDA breeding program initiated also a hybridization pipeline to further contribute to the development of germplasm. In 2003 the program became independent and the two CGIAR centers continue to collaborate closely ever since, today under the label of ONE Global Wheat Program.

In 1984 Algeria inscribed in its catalog the first ICARDA-derived cultivar under the name of Waha (syn. Cham1, Plc/Ruff//Gta/Rtte), which was obtained from pedigree selection of a CIMMYT-generated $F_{5}$ population. Sister lines of this cultivar were later released in Cyprus, Jordan, Lebanon, Portugal, Saudi Arabia, Sudan, Syria and Turkey to become one of the 10 most successful durum cultivars of all time. In 1989, Morocco released for its dry areas the cultivar Om Rabi 1 (syn. Cham 5, Jori/Haurani) obtained by ICARDA's hybridization program initiated nine years before. Sister lines of this cross between a CIMMYT elite and a Middle East landrace were later released in Algeria, Iran, Iraq, Jordan, Syria, Tunisia and Turkey, also resulting in one of the 10 most successful durum cultivars of all time. Until 2018, 130 varieties have been released in 22 countries using the ICARDA bred germplasm [2].

In 2012, after 35 years of continuous breeding work, ICARDA was obliged to relocate its work from Aleppo, Syria to Rabat, Morocco and Terbol, Lebanon due to the severe social unrest that preceded the civil war. Therefore, this represents an appropriate time to evaluate the achievements to date and define strategies for the next decade to continue serving the global community. The best measure of the work of breeders is to calculate the rate of genetic gain (GG), as this is a function of the main components of the selection process: accuracy, intensity, turn-around time and heritability of the trait. The easiest way to do so is to field evaluate side-by-side germplasm developed during different breeding eras. This approach is meant to control the effect of the interactions between genotypes, environments, and agronomic management, so to reveal the true GG generated via breeding alone. The germplasm can be classified in different breeding eras rather by assigning it based on the year of release, or the year when a certain yield trial was composed, or the year in which a given cross was made. While all three methods are valid, there are inherent differences between the three. GG calculated by the year of release accounts for more than breeding cycling alone, since it also factors a component of catalog testing and release restrictions, which varies between countries, and typically results in smaller GG. The use of trial year is more closely related to the actual breeding cycle, as it is normally not affected by external factors, but it does not protect from the possibility that certain elites are tested more than once, and it often results in higher-rates. Finally, the use of the cross year is probably the least affected from factors not under the control of the breeders and truly measures the genetic progress made from the moment a certain hybridization is decided and 
the time this is ready for yield testing. For this reason, this methodology was selected for this article.

The annual rate of GG for grain yield (GY) is routinely measured in all breeding programs, but its value changes greatly based on the strength of the breeding selection, the germplasm used, and the testing method. For instance, using data of CIMMYT durum wheat trials run across 44 international testing sites from 1983 to 2003, Ammar et al. [3] identified an annual increase in trials mean of $1.15 \%$, and the top five elites reached a yield advantage of $1.2 \%$ per year when tested in North Africa as ratio of the predominant cultivar Karim (syn. Yavaros). Instead, testing at four irrigated environments of 11 CIMMYT durum wheat cultivars released in Turkey from 1975 to 2000 revealed an annual rate of GG for GY equal to $0.76 \%$ [4], while field trials of twenty-nine durum cultivars released in Morocco between 1949 and 2016 at six sites revealed annual GG for GY of $0.43 \%$, mostly associated with selection for early flowering and higher harvest index [5]. A GG study conducted by De Vita et al. [6] at one site, over two seasons, and three agronomic treatments revealed an annual yield gain of $19.9 \mathrm{~kg} \cdot \mathrm{ha}^{-1}$ (calculated at $0.36 \%$ ) when comparing 18 Italian durum cultivars. These authors reported that the gain was mostly associated with a higher number of spikes per square meter. Comparing 24 Italian and Spanish durum wheat cultivars released between 1945 and 2000 across 12 field trials in Spain, confirmed an increase in yield per plant per year of $0.36 \%$ for the Italian material, and $0.44 \%$ for the Spanish program [7]. Also in this case the authors concluded that the number of spikes per plant had a significant effect on GY, but TKW did not contribute. A study of Canadian durum wheat cultivars released from 1947 to 2009 [8] and tested across several experimental farms revealed an annual rate of GG for GY of $0.69 \%$, but this value was also associated with $1 \%$ gain for protein concentration, a critical trait for Canada durum exports. Hence, the authors concluded that while GG for GY was made via increasing harvest index, the stringent industry requirements for top rheological characteristics has prevented the breeders to further accelerate their GG for GY. Field trials across three environments in South Australia revealed that 12 cultivars released between 1958 and 2007 reached an annual rate of GG for GY equal to $25 \pm 3.4 \mathrm{~kg} \cdot \mathrm{ha}^{-1}$ (calculated at $0.46 \%$ ) [9]. Finally, a study of 26 bread wheat elites form the CIMMYT program released between 1977 and 2008, tested across Mexico, Asia and Africa revealed a GG of $0.7 \%$ per year for grain yield, mostly associated with earlier flowering and large grain size [10].

In conclusion, the general rate of GG obtained from different programs around the world ranged from $0.36 \%$ when considering the release year of Italian cultivars, to $1.2 \%$ using the trial year of CIMMYT durum international nurseries tested in North Africa, and average around $0.6-0.7 \%$. Here, we assess the GG of the ICARDA durum wheat program across 10 environments using a representative set of germplasm from 
different decades, and we associate the grain yield rate change to various traits and to a decrease in genetic diversity.

\section{MATERIALS AND METHODS}

\section{Plant Material}

A total of 456 ICARDA's durum wheat elite lines spanning 35 years of breeding work were initially obtained from the gene bank and were grown in Terbol, Lebanon in 2014-15 season as short observation rows. For each accession, the year of origin was determined as the year when the cross was made and used it to assign it to a decade (1974-1984, 19851994, or 1995-2004). The decision of using “decades" instead of "year" for measuring genetic gain was made to account for the year-to-year variation in funds, available staff, agro-climatic variation, and research advances (i.e., molecular markers, planters, irrigation strategies, and others) which inevitably result in different annual rates of accuracy but have less average influence across decades. Further, the "decade" was considered a good unit of time to compare germplasm and obtain better statistical comparison with higher degrees of freedom.

A subset of 22 entries were selected as the most representative with 2, 9 , and 11 assigned to the first, second, and third decade, respectively. The decision was made to include only the two top yielding and rust resistant entries from the first decade to avoid positively biasing the rate of GG by including poor performing genotypes. This set of historical germplasm was placed in competition against a second set of elite lines from the fourth and most recent decade (2005-2011). This set changed each season and it was composed of new elites shipped each year by ICARDA as the International Durum Yield Trial nursery (IDYT) 39th, 40th, and 41st for a total of 11, 19, and 19 entries each, respectively, in season 2015-16 (16), 2016-17 (17), and 2017-18 (18). The full list is provided in Supplementary Table S1.

\section{Field Trials}

Both the historical and IDYT sets were increased to 24 genotypes each including commercial checks, for a total of 48 genotypes tested each season. However, only results for the genotypes tested for genetic gain (Table S1) are reported here. An alpha lattice design of two replications with subblocks of size four was used as experimental design. Each entry was planted in plots of $7.5 \mathrm{~m}^{2}$ at a rate of 250 grains per square meter. Seven research farms were used over the three seasons, six in Morocco and one in Lebanon, for a total of 10 environments (sites $\times$ seasons). The details of the stations and practices are provided in Table 1. Planting was conducted timely between the 15th of November and the 1st of December, weeds were controlled by tank mixtures of the herbicides Pallas and Cossak, and nitrogen fertilization was provided in split applications of 25 or 50 units based on moisture and the expected final yield. Flowering time was 
measured as days elapsing between germination until heading, when $50 \%$ of the plot showed awns emerging from the boot. Plant height was measured in $\mathrm{cm}$ from the base of the plant to the end of the spike without counting the awns. Spike per square meter was recorded as the number of fertile tillers within a $0.25 \mathrm{~m}^{2}$ surface and then multiplied by four. Days to maturity was recorded when $50 \%$ of the plot showed drying of the apical stem. Three weeks after maturity, the plots were harvested using a Zurn experimental plot combine after removing the two external rows $\left(5 \mathrm{~m}^{2}\right)$ and the weight was converted into grain yield (GY) measured as $\mathrm{kg} \cdot \mathrm{ha}^{-1}$. One thousand kernels (TKW) were counted and weighted on a precision balance and expressed in gr.

\section{Statistical Analysis}

The field recorded traits were analyzed independently for each environment. The best linear unbiased estimates (BLUEs) were calculated using the PBIB.test model of the library agricolae [11] on the free software $\mathrm{R}$ [12]. To combine the results of different genotypes across seasons, each accession was recognized by its decade assignment and the BLUEs used as values. The decades were then tested by ANOVA for different traits using the environments and individuals within a decade as the replicates, and decades $\times$ environment as the error by $l m$ model in R. The LSD differences of the combined analysis were determined using the LSD.test model of the package agricolae [11] in R [12].

All graphical representations were generated using Excel for bi-plot, bar graph, and box-whiskers. The trend line within environment and combined across environments was used to measure the slope of the regression equation between the four decades. This slope was then divided by the actual value of the fourth decade and expressed as the percentage of genetic gain (GG) over decades. The genetic gain per year was then measured dividing this value by 10 (years).

\section{Genotyping and Genetic Diversity}

Among the 456 initial set and the 49 IDYT, 200 entries were selected for genotyping. Leaf samples were collected from 3 weeks old seedling and submitted to LGC Genomics for full service DNA extraction and genotyping with 96 KASP markers evenly distributed across the durum wheat genome. A total of 60 resulted polymorphic in this set with a minor allele frequency (MAF) higher than 5\%, and less than $1 \%$ missing data. The markers were divided into two classes: the 50 most common loci (MAF > 10\%) and 10 most rare (MAF < 10\%). The average MAF of each entry was then calculated for the two markers classes, and it was used to test changes in molecular diversity over decades using a linear model with individuals within decade as replicates, as explained above. LSD statistically significant classes were also determined.

Fixation analysis (Fst) was conducted using MAF and testing for fixation between decades using the calculate.all.pairwise.Fst of the 
BEDASSLE package [13] in R [12]. Following the examples of [14,15], Fst values below 0.05 (5\%) were considered to be associated with free interbreeding between decades and no or low allelic fixation, while values above 0.10 (10\%) indicated strong isolation and allelic fixation, and Fst scores in between were interpreted as partial or minimum fixation.

The complete set of 60 markers was also used for kinship analysis using the adegenet package [16] in $\mathrm{R}$ and the discriminant analysis of principal components DAPC was run assuming a $k$ of four as it would be determined by the four decades considered here, and 20 PCs. Each elite was then assigned to a group and these were expressed within decades.

\section{RESULTS}

\section{Experimental Variation in Field Trials}

The ANOVA for individual environment revealed significant $(p<0.01)$ genotypic effect for all traits, and heritabilities for GY superior to 0.30 (Table 1). A total of 10 environments could be effectively used for the analysis with average yields ranging from $2187 \mathrm{~kg} \cdot \mathrm{ha}^{-1}$ for the harshest site (Annoceur 18) to $5508 \mathrm{~kg} \cdot \mathrm{ha}^{-1}$ for the most productive (Terbol 17). Hence, the test environment provided a good range of variation, with different soil types, agronomic practices, and moisture levels.

The combined analysis of variance across environments also showed a significant effect for Decade for all traits at $p<0.01$, except plant height with significance of $p<0.05$ (Table 2). The coefficient of variation for the traits was also below $15 \%$ for all traits, except for plant height, for which the moisture of each environment was more important than the Decade itself. 
Table 1. Experimental farms used for field evaluation.

\begin{tabular}{|c|c|c|c|c|c|c|c|c|c|}
\hline Site & Avg. GY & $h^{2} \mathbf{G Y}$ & Coordinates & Altitude (m) & Season & Soil & Moisture (mm) & Practices & Nitrogen $(\mathrm{U} \times$ split $)$ \\
\hline Annoceur 18 & 2187 & 0.74 & $\begin{array}{l}33^{\circ} 40^{\prime} 59.5^{\prime \prime} \mathrm{N}, \\
4^{\circ} 51^{\prime} 30.2^{\prime \prime} \mathrm{W}\end{array}$ & 1440 & 2017-18 & Lime-clay & 258 & $\begin{array}{l}\text { Rainfed, } \\
\text { conv. tillage }\end{array}$ & $25 \times 3$ \\
\hline Marchouch CT 16 & 3023 & 0.39 & $\begin{array}{l}33^{\circ} 34^{\prime} 3.1^{\prime \prime} \mathrm{N}, \\
6^{\circ} 38^{\prime} 0.1^{\prime \prime} \mathrm{W}\end{array}$ & 398 & 2015-16 & Clay vertisol & 290 & $\begin{array}{l}\text { Rainfed, } \\
\text { conv. tillage }\end{array}$ & $50 \times 3$ \\
\hline Marchouch CT 17 & 2777 & 0.78 & $\begin{array}{l}33^{\circ} 34^{\prime} 3.1^{\prime \prime} \mathrm{N}, \\
6^{\circ} 38^{\prime} 0.1 " \mathrm{~W}\end{array}$ & 398 & 2016-17 & Clay vertisol & 260 & $\begin{array}{l}\text { Rainfed, } \\
\text { conv. tillage }\end{array}$ & $50 \times 3$ \\
\hline Marchouch ZT 17 & 3147 & 0.85 & $\begin{array}{l}33^{\circ} 34^{\prime} 3.1^{\prime \prime} \mathrm{N}, \\
6^{\circ} 38^{\prime} 0.1^{\prime \prime} \mathrm{W}\end{array}$ & 398 & 2016-17 & Clay vertisol & 305 & $\begin{array}{l}\text { Rainfed, } \\
\text { zero tillage }\end{array}$ & $50 \times 3$ \\
\hline Marchouch ZT 18 & 5131 & 0.32 & $\begin{array}{l}33^{\circ} 34^{\prime} 3.1^{\prime \prime} \mathrm{N}, \\
6^{\circ} 38^{\prime} 0.1 " \mathrm{~W}\end{array}$ & 398 & 2017-18 & Clay vertisol & 490 & $\begin{array}{l}\text { Rainfed, } \\
\text { zero tillage }\end{array}$ & $50 \times 3$ \\
\hline Melk Zehr 18 & 4695 & 0.36 & $\begin{array}{l}30^{\circ} 2 ' 33^{\prime \prime} \mathrm{N}, \\
9^{\circ} 33^{\prime} 4 " \mathrm{~W}\end{array}$ & 137 & 2017-18 & Sandy limestone & 450 & Fertigation & $25 \times 6$ \\
\hline Sidi el Aydi 18 & 4064 & 0.30 & $\begin{array}{l}33^{\circ} 9^{\prime} 36^{\prime \prime} \mathrm{N}, \\
7^{\circ} 24^{\prime} 0^{\prime \prime} \mathrm{W}\end{array}$ & 226 & 2017-18 & Vertisol & 410 & $\begin{array}{l}\text { Rainfed, } \\
\text { conv. Tillage }\end{array}$ & $50 \times 2$ \\
\hline Terbol 17 & 5508 & 0.65 & $\begin{array}{l}33^{\circ} 48^{\prime} 29^{\prime \prime} \mathrm{N}, \\
35^{\circ} 59^{\prime} 22^{\prime \prime} \mathrm{W}\end{array}$ & 897 & 2016-17 & Chromic vertisol & 510 & $\begin{array}{l}\text { Suppl. irrigation, } \\
\text { conv. tillage }\end{array}$ & $50 \times 3$ \\
\hline Terbol 18 & 3739 & 0.78 & $\begin{array}{l}33^{\circ} 48^{\prime} 29^{\prime \prime} \mathrm{N}, \\
35^{\circ} 59^{\prime} 22^{\prime \prime} \mathrm{W}\end{array}$ & 897 & 2017-18 & Chromic vertisol & 415 & $\begin{array}{l}\text { Suppl. irrigation, } \\
\text { conv. tillage }\end{array}$ & $50 \times 3$ \\
\hline Tessaout 18 & 4467 & 0.34 & $\begin{array}{l}29^{\circ} 49^{\prime} 48^{\prime \prime} \mathrm{N}, \\
8^{\circ} 34^{\prime} 48^{\prime \prime} \mathrm{W}\end{array}$ & 472 & 2017-18 & Calcic xerosol & 495 & $\begin{array}{l}\text { Gravity irrigation, } \\
\text { conv. tillage }\end{array}$ & $50 \times 3$ \\
\hline
\end{tabular}


Table 2. Combined analysis of variance across environments.

\begin{tabular}{|c|c|c|c|c|c|c|c|c|c|c|c|c|c|c|}
\hline \multirow{3}{*}{$\begin{array}{l}\text { Trait } \\
\text { Grain yield }\end{array}$} & \multirow{3}{*}{$\begin{array}{l}\text { DF } \\
\text { Env } \\
9 \\
\end{array}$} & \multicolumn{4}{|c|}{ Ratio of variance } & \multirow{3}{*}{$\begin{array}{l}\text { CV } \\
14.7 \\
\end{array}$} & \multicolumn{8}{|c|}{ Decades (average) } \\
\hline & & \multicolumn{2}{|c|}{ Decade } & \multicolumn{2}{|c|}{ Env } & & \multicolumn{2}{|c|}{$\begin{array}{c}1975- \\
1984\end{array}$} & \multicolumn{2}{|c|}{$\begin{array}{c}1984 \\
-1993 \\
\end{array}$} & \multicolumn{2}{|c|}{$\begin{array}{r}1994 \\
-2003 \\
\end{array}$} & \multicolumn{2}{|c|}{$\begin{array}{c}2004- \\
2011 \\
\end{array}$} \\
\hline & & 0.16 & $* *$ & 0.82 & $* *$ & & 3448 & $\mathrm{c}$ & 3730 & $\mathrm{c}$ & 3986 & $\mathrm{~b}$ & 4329 & $\mathrm{a}$ \\
\hline Days to heading & 6 & 0.05 & $* *$ & 0.94 & $* *$ & 5.1 & 113 & $\mathrm{a}$ & 111 & $\mathrm{a}$ & 109 & $\mathrm{~b}$ & 105 & c \\
\hline Days to maturity & 2 & 0.00 & $* *$ & 0.99 & $* *$ & 1.9 & 159 & $\mathrm{a}$ & 159 & $\mathrm{ab}$ & 157 & $\mathrm{~b}$ & 155 & c \\
\hline Plant height & 6 & 0.25 & $*$ & 0.47 & $* *$ & 19.2 & 89 & $\mathrm{~b}$ & 101 & $\mathrm{a}$ & 99 & $\mathrm{ab}$ & 92 & $\mathrm{~b}$ \\
\hline Spikes per square meter & 8 & 0.04 & $* *$ & 0.93 & ** & 11.2 & 477 & $\mathrm{c}$ & 508 & $\mathrm{bc}$ & 519 & $\mathrm{ab}$ & 534 & $\mathrm{a}$ \\
\hline 1000-kernels weight & 4 & 0.05 & $* *$ & 0.94 & $* *$ & 9.8 & 43 & $\mathrm{a}$ & 39 & $\mathrm{~b}$ & 41 & $\mathrm{a}$ & 37 & c \\
\hline
\end{tabular}

DF, degrees of freedom; Env, environment; CV, coefficient of variation; *, $p<0.05 ;{ }^{* *}, p<0.01$

\section{Environment Specific Genetic Gain}

The GG for each decade of breeding work was assessed for GY at each environment (Figure 1). The lowest average GG was recorded at $0.1 \%, 0.7 \%$, 2.9\%, and 4.7\% in Annoceur 18, Terbol 17, Marchouch ZT 17, Sidi el Aydi 18, and Marchouch ZT 18, respectively. Medium rates of average GG were recorded at $6.3 \%$, and $7.0 \%$ for Tessaout 18 , and Melk Zehr 18, respectively. The highest rates of GG were measured at 9.9\%, $14.3 \%$, and $14.8 \%$ for Marchouch CT 17, Marchouch CT16, and Terbol 18, respectively. As a clarification, these GG rates are measured across decades, hence to derive the annual rate of GG the presented values need to be divided by 10 .

However, the average rate of GG is a function of both good and bad elites developed in each decade, while breeders are often interested in the absolute best ones. As such, GG was also measured only for the absolute top yielding elite of each decade. In this case, the lowest GG was measured at $-1.1 \%$ and $3.0 \%$ for Annoceur 18 and Terbol 17, respectively. Medium rates were achieved in Marchouch ZT 17 with $7.1 \%$, while high GG rates were measured at 9.3\%, 9.6\%, 9.8\%, 12.3\%, 13.6\%, 13.9\%, and $15.3 \%$ in Marchouch ZT 18, Melk Zehr 18, Sidi el Aydi 18, Tessaout 18, Terbol 18, Marchouch CT 17, Marchouch CT 16, respectively. 


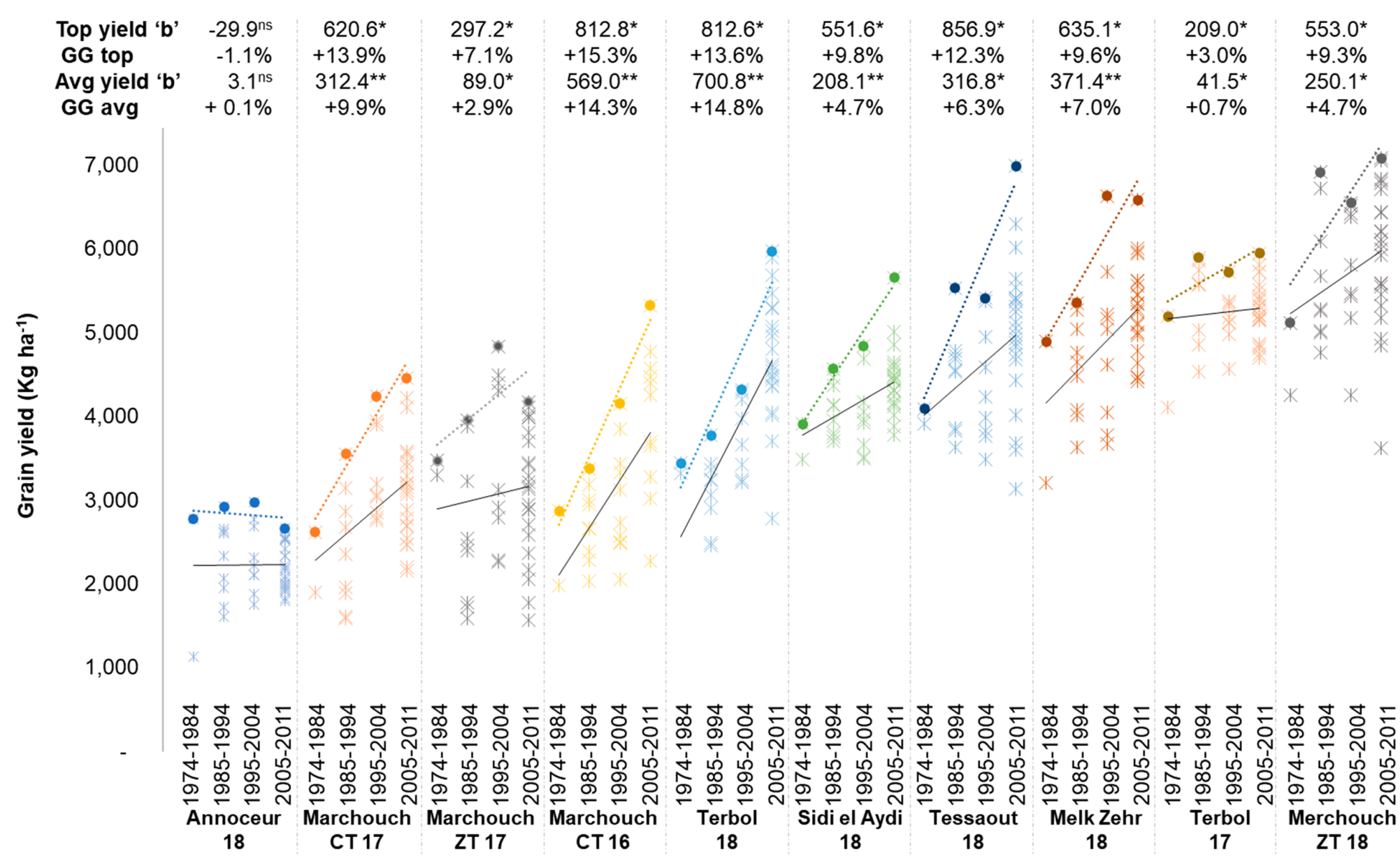

Figure 1. Performances of ICARDA elite germplasm from different decades (1975-1984, 1984-1993, 1995-2004, 2005-2011) for grain yield across 10 experimental farms in Morocco and Lebanon. The name of the farm is reported under the decade together with the season of testing (17 or 18). The value of each tested elite is reported as a star symbol, while the top yielding line for each decade is reported as a solid circle. For each site both the average (Avg yield) and Top yield trendlines are presented, and the slope of their equation ("b") is reported on the top part of the figure, with significance levels $\left(^{*}, p<0.05\right.$; ${ }^{* *}, p<0.01$ ) for $\mathrm{b} \neq 0$. The decades genetic gain (GG) for both the average (avg) and top lines was calculated as the "b" slope of the trendline equation divided by the average or top grain yield value for the last decade. 


\section{Genetic Gain across Environments}

The combined analysis across environments showed a decade-wise GG for GY of 7\%, equal to $0.7 \%$ per year (Figure 2), with a significant variation from $3448 \mathrm{~kg} \cdot \mathrm{ha}^{-1}$ in $1974-1984$ to $4329 \mathrm{~kg} \cdot \mathrm{ha}^{-1}$ in 2005-2011, or a $25 \%$ yield increase via 35 years of breeding efforts (Table 2). To define which selection strategy better explained this GG rate, five additional traits were considered (Figure 2).
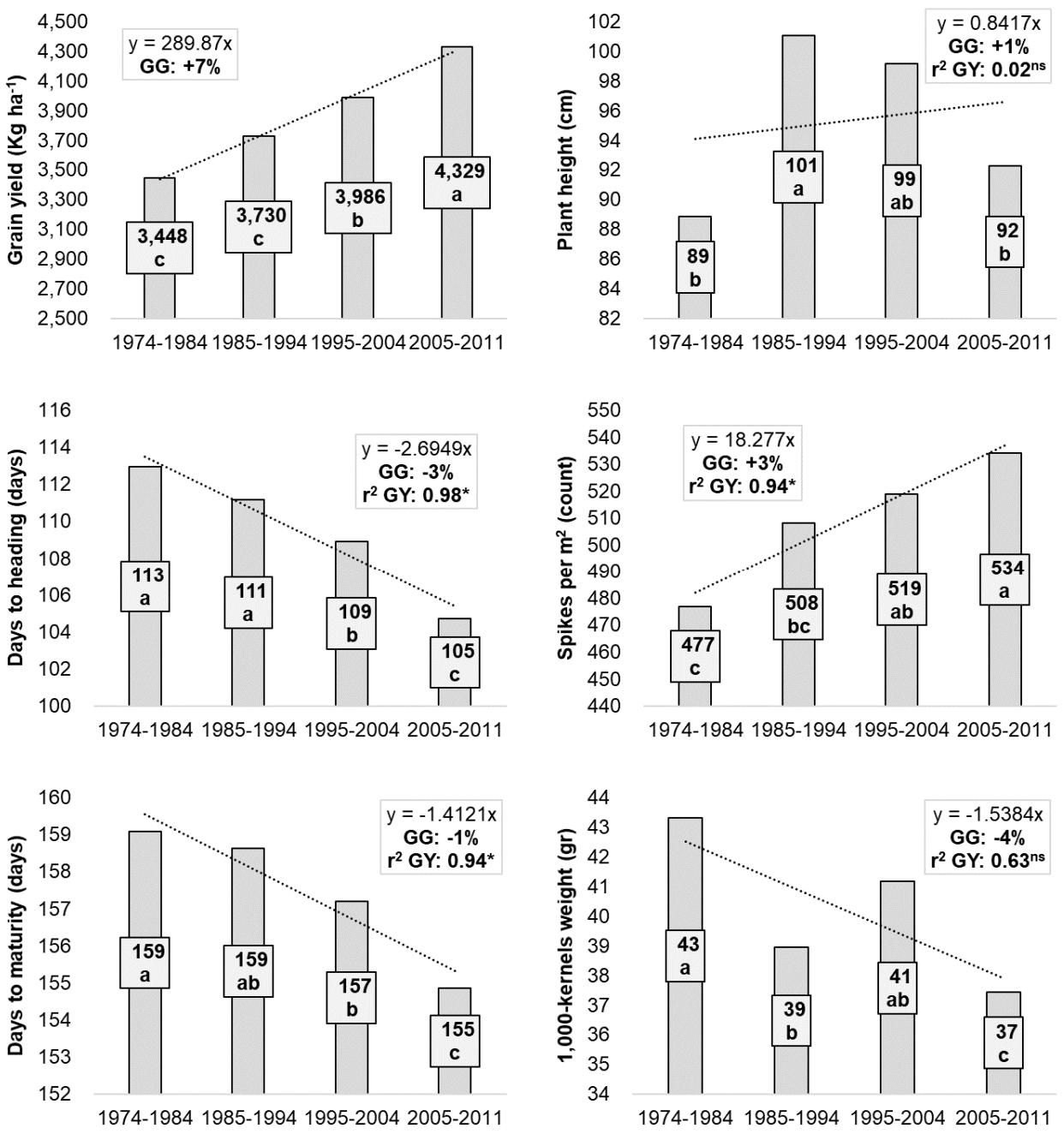

Figure 2. Performances of ICARDA elite germplasm across decades (1975-1984, 1984-1993, 1995-2004, 20052011) for six traits. The decade represents the year when the cross was made to obtain the given germplasm. The values represented by the bars are the averages of each decade, and the actual value is provided with its letter designation based on LSD discrimination. The trend line for each trait is reported together with the corresponding slope equation. The decades genetic gain (GG) was calculated as the 'b' slope of the trendline equation divided by value for the last decade. Also, the value of the regression between a given trait and grain yield is presented as $r^{2} \mathrm{GY}$ and tested at $p<0.01$.

Plant height GG was measured at 1\%, with no significant effect on the GY; similarly grain size (TKW) decreased by $-4 \%$ over decades, changing from an average of 43 grams (gr) when the ICARDA program started to 
$37 \mathrm{gr}$ in the most recent decade. Instead, flowering time (days to heading) was effectively reduced from 113 to 105 days with a GG of $-3 \%$, and this explained up to $98 \%$ of the decade-wise variation for GY. Similarly, the selection for early-maturing germplasm (159 to 155 days) contributed to the increase in GY $\left(r^{2}=0.94, p<0.01\right)$. Finally, spike density (spike per square meter) was also effectively increased at a rate of $3 \%$ per decade from 477 to 534, explaining up to $94 \%$ of the gain for GY.

(A) Common alleles Minor allele frequency

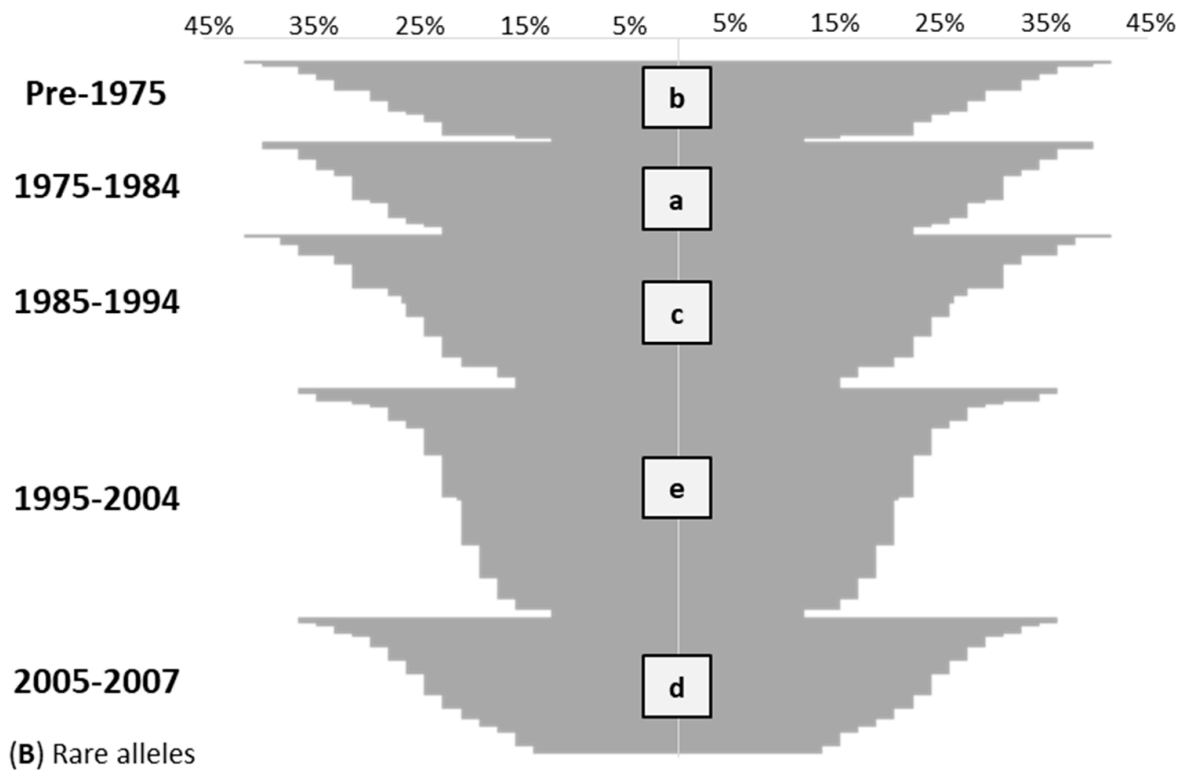

B) Rare alleles
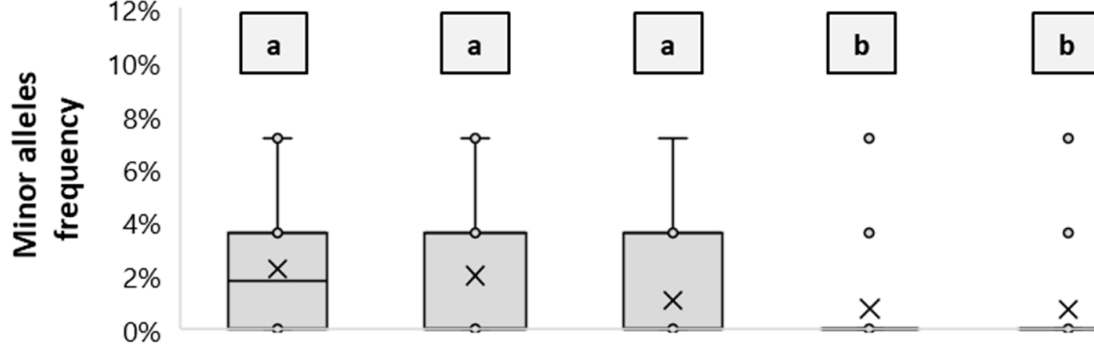

Pre-1975 1975-1984 1985-1994 1995-2004 2005-2007

Figure 3. (A) The frequency of minor alleles for the 50 most common alleles is reported for each individual in the funnel graph and sorted from most-to-less within each decade. The LSD classes of each decade is reported with letters. (B) The average frequency of minor alleles for rare alleles is presented as the horizontal lines in the box-whiskers graph, while the ' $\mathrm{X}$ ' represents the median, the edges of the box the 3rd and 2nd quartiles, the whiskers the 4th and 1st quartile, and the circles the outliers. The LSD classes of each decade is reported with letters.

\section{Genetic Gain for Allelic Diversity}

Using 60 polymorphic markers and 200 ICARDA's elites generated in four different decades it was possible to measure the effect of imposing breeding selection on overall genetic diversity. The frequency of minor alleles is a good measurement of the number of loci that are still 
segregating within a breeding program. This was calculated first for 50 common alleles, with the minor allele present in more than $10 \%$ of the population under study (Figure 3), and significant decade effect was found. The germplasm produced between 1975 and 1984 had the highest average rate, with $30.7 \%$ of the 50 loci tested still segregating, followed by germplasm pre-1975 (28.0\%), then 1985-1994 (26.0\%), 2005-2007 (23.7\%), and 1995-2004 (21.7\%). This suggests that $6.3 \%$ of the total genetic diversity was eroded over 35 years of breeding selection. In addition, also the best individual elite changed from $41 \%$ of the loci segregating Pre-1975, to $36 \%$ in the last decade (2005-2007).

The same calculations were also done for the 10 most rare alleles, with the minor allele present in less than $10 \%$ of the population under study (Figure 3). It also showed significant decade effect $(p<0.01)$. In this case the change was even more radical with $2.2 \%$ and $2.10 \%$ of the lines segregating for these loci Pre-1975 and 1975-1984, to 1.0\% in 1985-1994, to $0.7 \%$ in the last two decades.

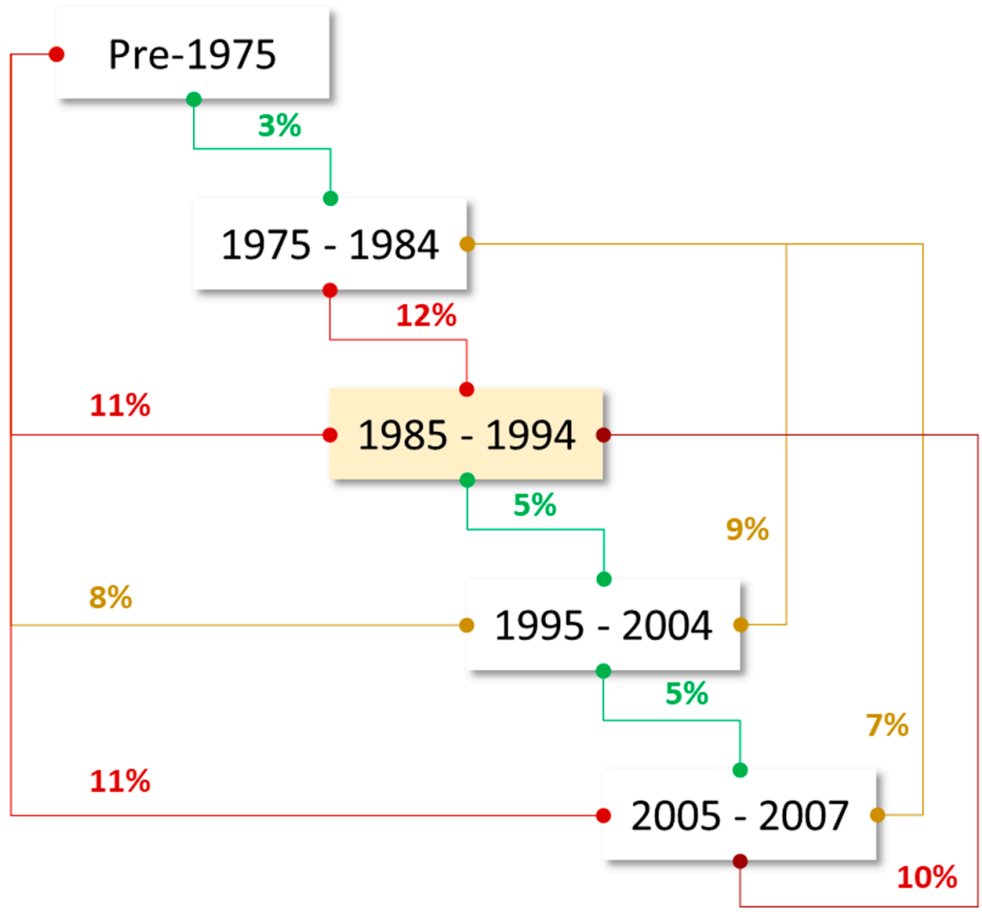

Figure 4. Evaluation of erosion of genetic diversity among different breeding decades via the fixation index (Fst). The lines connected the decades indicate the relationship tested, and the relative Fst value is presented in percentage. Values below $5 \%$ are considered to represent free sharing of alleles and are color coded in green. Values above 10\% indicate isolation occurred, and are presented in red. Values in between indicate partial fixation of alleles and are presented in yellow.

The fixation index (Fst) provides a measure of allelic fixation, and hence loss of diversity, occurring between different breeding decades (Figure 4). There is good sharing of alleles and admixture (Fst $<5 \%$ ) between all successive decades, as it can be expected by crossing strategies 
that take advantage of the germplasm generated in the previous seasons. However, there is strong fixation between 1975-1984 and 1985-1994 when the Fst value reached $12 \%$, indicating a clear isolation from the alleles used in the previous decades. Looking at non-subsequent decades, Fst are also indicative of allelic fixation and migration over time, with non-admixture values (>10\%) in most cases, except for the germplasm of 1975-1984 that was apparently recycled in the later crosses.
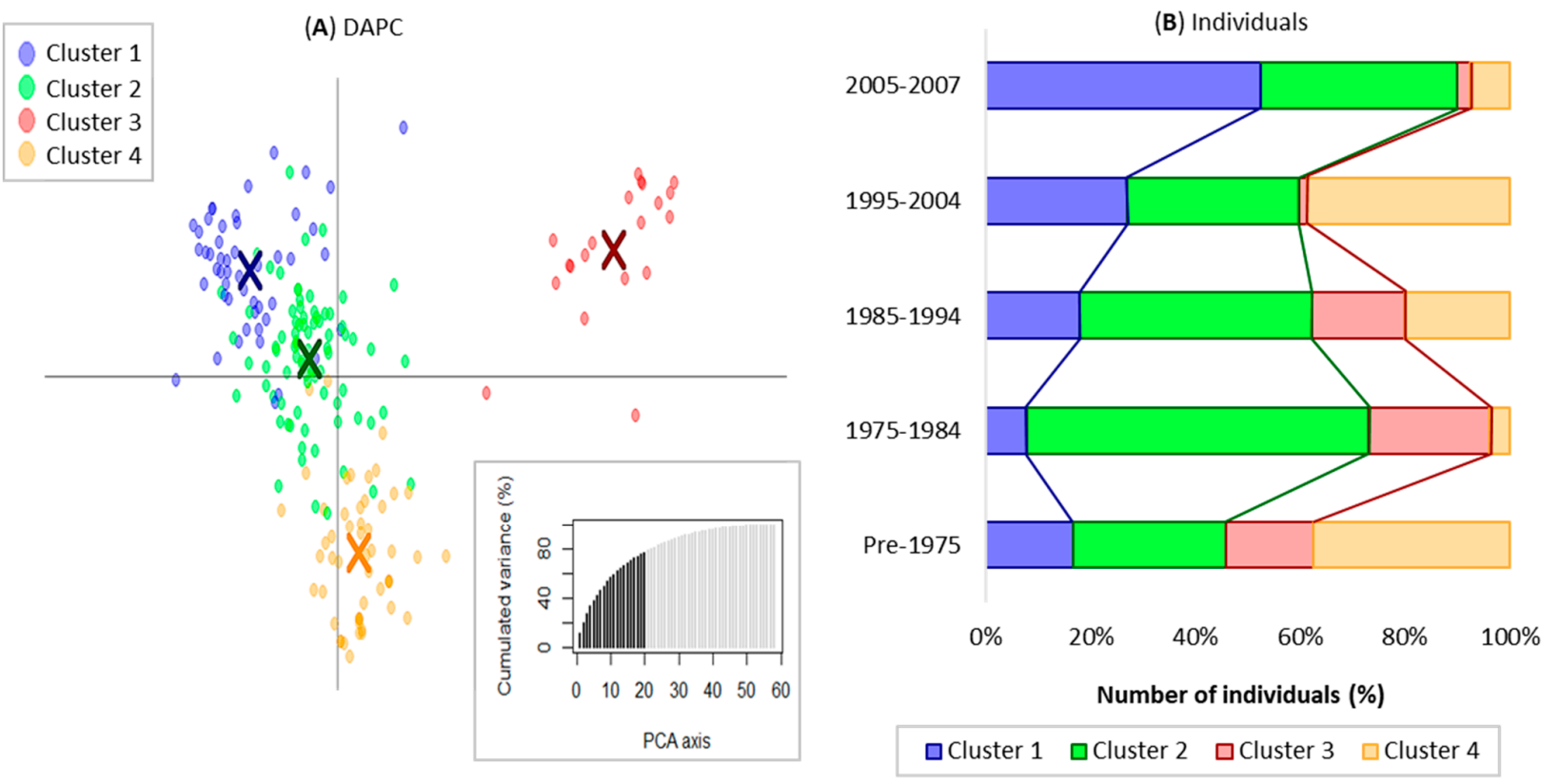

Figure 5. Clustering based on genetic diversity of ICARDA elites by DAPC algorithm. (A) The distribution of the individuals based on the two main PCs is presented and the cluster assignment is color coded as per legend. (B) The distribution of individuals per clusters within each decade is also presented and color coded as per legend.

To better understand the kinship relationships among the elite lines under study a DAPC analysis was conducted, testing the hypothesis that each decade would generate its own cluster, $k=4$ (Figure 5). Cluster 1 was the most abundant in the last decade (2005-2007) and its presence raised steadily over the years. This cluster incorporates several of the most successful ICARDA's elites and cultivars, and these can be traced back to the CIMMYT founders Korfila (DS15/Geier), Loukos (Ruff/Fg//Trob), and Bicre (Bittern/Creso). Cluster 2 was mostly present in 1975-1984 and in the last decade, and it incorporated many of the CIMMYT post Green Revolution elites. Cluster 3 was most abundant in 1975-1984 and it substantially disappeared in the following decades. This cluster incorporates several of the initial ICARDA's crosses between CIMMYT's elites and landraces, such as the ICARDA most successful cultivar Om Rabi (Jori/Haurani). Finally, cluster 4 was most represented in 1995-2004 and Pre-1975, while it became under-represented in 1975-1984 and 2005-2007 crosses. This sub-population is rich in crosses made between Pre-1975 
CIMMYT's elites and crop wild relatives, and it includes the recent released cultivar Nachit (Amedakul1/Triticum dicoccoides Syria//Loukos). Based on this analysis, it is possible to notice how the genetic background of some of the funder parental lines of Clusters 3 and 4 have substantially disappeared in the last decade, Cluster 2 has remained nearly the same over crossing cycles, while Cluster 1 germplasm increased significantly.

\section{DISCUSSION}

\section{Lessons Learned from Environment-Specific Genetic Gain Analysis}

Since its inception the ICARDA durum wheat breeding effort has been dedicated to the development of cultivars well adapted to drought conditions, with some significant success stories. Still the GG measured across environments does not show an evident trend in favor only to dry conditions. In fact, Annoceur 18 was the most drought-prone of the sites used for testing and substantially no GG was achieved here. This is probably because Annoceur is located at $>1400 \mathrm{~m}$ above sea level in the Atlas Mountains, where spring drought occurs in combination with severe cold temperatures during winter. This type of climatic conditions has not been previously targeted by the program and to date, no ICARDA's cultivar has been released for these types of cold and dry agro-ecologies. Only recently a facultative winter durum breeding effort was initiated to try and serve these remote and harsh regions.

Additionally, the comparison of GG for the top yielding lines in Marchouch 17 using side-by-side conventional vs. zero-till planting have also shown how the program could reach higher GG when normal tillage was deployed (13.9\% vs. 7.1\%). This result has prompted the consideration to incorporate zero-till planting in the selection process to better skew the germplasm toward adapting to this important management practice, ideal for drylands farming. In all other environments it was possible to measure $>0.9 \%$ yearly rates of GG for the top yielding lines, except for Terbol 17 where only $0.3 \%$ could be recorded. Since 2012, Terbol has become a major site for ICARDA breeding selection and it was already possible to measure good positive effect in Terbol 18 when the rate of GG raised to $1.4 \%$.

Instead, the low average GG across sites, with five environments showing $<0.5 \%$ annual rate, can be attributed to the ICARDA's mandate of generating germplasm for several agro-ecologies across countries. In the early years, this requirement was addressed by generating mega-cultivars moderately adapted to all environments. In the last decade this approach was abandoned, in favor of selecting for stable $(G \times E)$ elites highly adapted to one agro-ecology, but not necessarily to all. As such, the balance between top and bad yielding lines tested across different environments results in low averages. This can clearly be seen from the analysis, with excellent rates of GG when considering the top performers, but only 
moderate rates when considering the average of the decades. Still, a clear positive progression can also be observed when considering the averages.

\section{Lessons Learned from across-Environment Genetic Gain Analysis}

The average decade GG for GY across environment was measured at $0.7 \%$ per year. This value is well in line with [10] that analyzed GG following a similar approach to what was presented here for the CIMMYT bread wheat program, and it is higher than what was reported by other authors for durum wheat [4-9], but it falls below the 1.2\% GG declared by CIMMYT durum wheat program using trial year across locations [3]. Overall, the GG obtained shows a good positive trend and it is within the range presented by other authors. Furthermore, this is particularly positive when considering that half of the test sites used for the analysis are prone to severe terminal droughts. In a study of the CIMMYT's SemiArid bread Wheat Yield Trials (SAWYT), Bradburd et al. [13] reported that annual GG for grain yield was $0.19 \%$ in drought-prone environments with average yields below $4000 \mathrm{~kg} \cdot \mathrm{ha}^{-1}$, while it reached $0.49 \%$ under more favorable conditions. Moreover, the analysis showed how the yield gain was obtained by selecting for earlier germplasm with high number of spikes per square meter. This is in good agreement with what found by [57], whom also confirmed these traits as the most affected by breeding selection over time in Italy, Spain, and Morocco. Further, both traits are considered to be advantageous for adaptation to drought and changing climates [17-22]. However, grain size was reduced through the selection process as experienced by [6,7]. This trait is extremely important for the pasta and couscous industry as it is highly related with semolina yields. As such, it would be important to concentrate future efforts to increase TKW, without losing the achieved GG for spike density. On the other hand, it would not be advisable to attempt to further increase yield by selecting even earlier flowering germplasm, as a shorter vegetative phase might ultimately result in a yield penalty when moisture is still available in the soil.

\section{Erosion of Genetic Diversity}

The 35 years of hybridizations and breeding selection have resulted in severe depletion of genetic diversity. The measurement of minor allele frequency revealed that $6.3 \%$ of the diversity has been lost over the four decades. More alarmingly, the genetic diversity for rare alleles has been decreased 3-folds since the inception of the breeding program. The fixation index analysis revealed very clearly the beginning of the ICARDA's own hybridization pipeline in 1981, with a clear isolation occurring between the CIMMYT germplasm used for breeding before 1984, and the introduction of different alleles since the hybridization started. This can be trace back to the substantial disappearance in the last decade of germplasm belonging to Cluster 3 and Cluster 4, which encompass several hybrids between elites, landraces, and crop wild relatives. Hence, since 
2012 a new hybridization strategy was defined to re-introduce novel and rare alleles from these types of diverse germplasms [23,24]. In a study across a global panel of durum wheat, Kabbaj et al. [25] revealed that modern breeding programs around the World have been very successful in capturing high rates of allelic diversity for common and rare alleles, with ICARDA's program maintaining more than $51 \%$ of loci not in fixed state, and 3\% of the global richness of rare alleles. This indicates that it is possible to maintain high diversity, while making steady progress in GG for several traits. In fact, the lack of diversity might become the major limiting factor to GG progress, and for this scope the steady introduction of exotic germplasm via hybridization remains the most strategic choice.

\section{CONCLUSIONS}

Genetic gain studies represent ideal opportunities for reflection on breeding strategies and achievements. Here, it was possible to confirm that the ICARDA's durum wheat program has been able to achieve a $0.7 \%$ rate of GG per year over the past 35 years, mostly through the reduction of the vegetative phase and the simultaneous increase in the number of fertile tillers. Still, some reduction in grain size (TKW) could be identified, and future exploitation of this useful trait presents a good opportunity for further increasing yield. In eight of the environments tested, the annual rate of GG was actually superior to $0.9 \%$, with four cases exceeding $1.0 \%$. For the two environments with low GG rates, a strategic decision has been made for the next decade to specifically target a facultative winter durum program for the Atlas Mountains, and to shift the sowing of all breeding trials to zero-till at the main station of Marchouch. Moreover, the good GG observed was obtained through a severe erosion of the available genetic diversity. Hence, a new approach has been put in place to incorporate more rare alleles in the hybridization process.

ICARDA holds a global responsibility to develop and provide free of charge new and useful elites to durum wheat breeders around the World. The results presented here are encouraging in light of the daunting threat of climate change. If the GG obtained by breeders can be coupled with equal advances made by agronomists, it might be possible to achieve the $>1.6 \%$ annual rate of wheat yield increase deemed to be sufficient to keep up with the surge in the global population [26].

\section{SUPPLEMENTARY MATERIALS}

The following supplementary materials are available online at https://doi.org/10.20900/cbgg20190004, Supplementary Table S1: Pedigree of entries used for testing the genetic gain of ICARDA's breeding program. 


\section{AUTHOR CONTRIBUTIONS}

FMB and MMN designed the study. FMB performed the experiments. MMN generated the germplasm. FMB wrote the paper with input from all authors.

\section{CONFLICTS OF INTEREST}

The authors declare that they have no conflicts of interest.

\section{FUNDING}

This research was funded by CRP WHEAT and by the Australian Grains Research and Development Corporation (GRDC) under grant number ICA00012: Focused improvement of ICARDA/Australia durum germplasm for abiotic tolerance.

\section{ACKNOWLEDGMENTS}

The authors wish to thank Rachid Abdelaziz and Rukoz Abu Nakad for the technical support in conducting the field trials.

\section{REFERENCES}

1. Tadesse W, Nachit M, Abdalla O, Rajam S. Wheat breeding at ICARDA: achievements and prospects in the CWANA region. In: Angus W, Bonjean A, van Ginkel M, editors. The world wheat wook: a history of wheat breeding. Paris (France): Lavoisier; 2016.

2. Lantican MA, Braun HJ, Payne TS, Singh RG, Sonder K, Baum M, et al. Impacts of international wheat improvement research: 1994-2014. El Batan (Mexico): CIMMYT; 2016.

3. Ammar K, Lage J, Villegas D, Crossa J, Hernandez H, Alvarado G. Association among durum wheat international testing sites and trends in yield progress over the last twenty-two years. In: Reynolds MP, Pietragalla J, Braun HJ, editors. International Symposium on wheat yield potential: challenges to international wheat breeding. El Batan (Mexico): CIMMYT; 2008. p. 108-12.

4. Barutcular C, Koc M, Tiryakioglu M, Yazar A. Trends in performance of Turkish durum wheats derived from the International Maize and Wheat Improvement Center in an irrigated West Asian and North African environment. J Agr Sci. 2006;144(4):317-26. doi: 10.1017/S0021859606006150

5. Taghouti M, Nsarellah N, Gaboun F, Rochdi A. Multi-environment assessment of the impact of genetic improvement on agronomic performance and on grain quality traits in Moroccan durum wheat varieties of 1949 to 2017. Glob Sci Res J. 2017;4(7):394-404.

6. De Vita P, Li Destri Nicosia O, Nigro F, Platani C, Riefolo C, Di Fonzo N, et al. Breeding progress in morpho-physiological, agronomical and qualittative traits of durum wheat cultivars released in Italy during the $20^{\text {th }}$ century. Europ J Agron. 2007;26:39-53. doi: 10.1016/j.eja.2006.08.009

7. Royo C, Alvaro F, Martos V, Ramdani A, Isidro J, Villegas D, Garcia del Moral LF. Genetic changes in durum wheat yield components and associated traits 
in Italiana and Spanish varieties during the $20^{\text {th }}$ century. Euphytica. 2007;155:259-70. doi: 10.1007/s10681-006-9327-9

8. Clarke JM, Clarke FR, Pozniak CJ. Forty-six years of genetic improvement in Canadian durum wheat cultivars. Canadian J Plant Sci. 2010;90(6):791-801. doi: 10.4141/cjps10091

9. Sadras VO, Lawson C. Genetic gain in yield and associated changes in phenotype, trait plasticity and competitive ability of South Australian wheat varieties released between 1958 and 2007. Crop Pasture Sci. 2011;62(7):533-49. doi: 10.1071/CP11060

10. Lopes MS, Reynolds MP, Manes Y, Singh RP, Crossa J, Braun HJ. Genetic yield gains and changes in associated traits of CIMMYT spring bread wheat in a historic set representing 30 years fo breeding. Crop Sci. 2011;52(3):1123-31. doi: 10.2135/cropsci2011.09.0467

11. De Mendiburu F. Una herramienta de analisis estadistico para la investigacion agricola. Tesis. Universidad Nacional de Ingenieria (UNIPERU)(Peru): Lima; 2009. Spanish.

12. R Development Core Team. R: a language and environment for statistical computing. Vienna (Austria): R Foundation for Statistical Computing; 2016.

13. Bradburd GS, Ralph PL, Coop GM. Disentangling the effects of geographic and ecological isolation on genetic differentiation. Evolution. 2013;67(11):3258-73. doi: 10.1111/evo.12193

14. Frankham R, Ballou JD, Briscoe DA. Introduction to conservation genetics. Cambridge (UK): Cambridge University Press; 2002.

15. Joukhadar R, Daetwyler HD, Bansal UK, Gendal AR, Hayden MJ. Genetic diversity, population structure and ancestral origin of Australian wheat. Front Plant Sci. 2017;8:2115. doi: 10.3389/fpls.2017.02115

16. Jombart T, Ahmed I. adegenet 1.3-1: new tools for the analysis of genome-wide SNP data. Bioinformatics. 2011;27(21):3070-1. doi: 10.1093/bioinformatics/btr521

17. Trethowan RM, van Ginkel M, Rajaram S. Progress in breeding wheat for yield and adaptation in global drought affected environments. Crop Sci. 2002;42(5):1441-6. doi: 10.2135/cropsci2002.1441

18. Marti J, Slafer GA. Bread and durum wheat yields under a wide range of environmental conditions. Field Crop Res. 2014;156:258-71. doi: 10.1016/j.fcr.2013.10.008

19. Maccaferri M, Sanguineti MC, Corneti S, Ortge JL, Salem MB, Bort J, et al. Quantitative trait loci for grain yield and adaptation of durum wheat (Triticum durum Desf.) across a wide range of water availability. Genetics. 2008;178(1):489-511. doi: 10.1534/genetics.107.077297

20. Monneveux P, Jing R, Misra SC. Phenotyping for drought adaptation in wheat using physiological traits. Front Physiol. 2012;3:429. doi: 10.3389/fphys.2012.00429

21. Bassi FM, Sanchez-Garcia M. Adaptation and stability analysis of ICARDA durum wheat elites across 18 countries. Crop Sci. 2017;57:2419-30. doi: 10.2135/cropsci2016.11.0916 
22. Alahmad S, el Hassouni K, Bassi FM, Dinglasan E, Youssef C, Quarry G, et al. A major root architecture QTL responding to water limitation in durum wheat. Front Plant Sci. 2019;10:436. doi: 10.3389/fpls.2019.00436

23. Zaim M, el Hassouni K, Gamba F, Filali-Maltouf A, Belkadi B, Sourour A, et al. Wide crosses of durum wheat (Triticum durum Desf.) reveal good disease resistance, yield stability, and industrial quality across mediterranean sites. Field Crops Res. 2017;214:219-27.

24. Tadesse W, Amri A, Sanchez-Garcia M, El-Bouhssini M, Karrou M, Patil S, et al. Improving wheat production in the Central and West Asia and North Africa (CWANA) region. In: Langridge $P$, editor. Achieving sustainable cultivation of wheat. London (UK): Burleigh Dodds Science Publishing Limited; 2017. p. 32749. doi: $10.4324 / 9781351114288$

25. Kabbaj H, Sall AT, Al-Abdallat A, Geleta M, Amri A, Filali-Maltouf A, et al. Genetic diversity within a global panel of durum wheat (Triticum durum) landraces and modern germplasm reveals the history of alleles exchange. Front Plant Sci. 2017;18(8):1277. doi: 10.3389/fpls.2017.01277

26. Fisher G. World food and agriculture to 2030/50: how do climate change and bioenergy alter the long-term outlook for food, agricolture and resource availability? In: Proceedings of the Expert Meeting on How to Feed the World in 2050. Rome (Italy): FAO Headquarters; 2009. ISBN: 978-92-5-106363-7

How to cite this article:

Bassi FM, Nachit MM. Genetic gain for yield and allelic diversity over 35 years of durum wheat breeding at ICARDA. Crop Breed Genet Genom. 2019;1:e190004. https://doi.org/10.20900/cbgg20190004 